\title{
Co-crystals of an organic tris-selenocyanate with ditopic Lewis bases: recurrent chalcogen bond (ChB) interactions motifs
}

Asia Marie S. Riel, Olivier Jeannin, Orion B. Berryman, and Marc Fourmigué

\section{SUPPLEMENTARY INFORMATION}

Table S1. Atomic coordinates of tris(selenocyanatomethyl)-2,4,6-trimethylbenzene 1 after optimization.

\begin{tabular}{c} 
Atom \\
\hline C \\
C \\
C \\
C \\
C \\
C \\
C \\
H \\
H \\
C \\
H \\
H \\
H \\
C \\
H \\
H \\
C \\
H \\
H \\
H \\
C \\
H \\
H \\
C \\
H \\
H \\
H \\
C \\
C \\
C \\
N \\
N \\
N \\
Se \\
Se \\
Se
\end{tabular}

$$
\begin{array}{r}
-0.29828600 \\
-1.01864700 \\
-0.53104800 \\
0.65031600 \\
1.35278200 \\
0.89977600 \\
-0.76171600 \\
0.03149800 \\
-1.19965400 \\
-2.29945900 \\
-2.14683400 \\
-3.08655400 \\
-2.70189900 \\
-1.27262900 \\
-1.76496100 \\
-0.64544400 \\
1.20166600 \\
1.16042400 \\
0.64999900 \\
2.24471300 \\
2.58098300 \\
2.77199500 \\
2.54202000 \\
1.67775500 \\
2.01702700 \\
1.07151600 \\
2.57506800 \\
-1.58714600 \\
-2.00989000 \\
4.05584500 \\
-1.18781600 \\
-1.51618600 \\
3.92090100 \\
-2.28289400 \\
-2.86192100 \\
4.32484300
\end{array}
$$

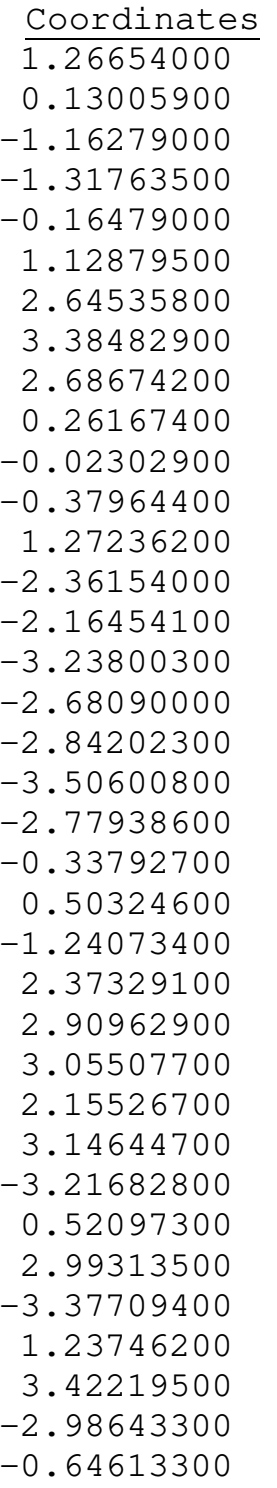

$-0.69880800$

$-1.11398700$

$-0.80489400$

$-0.05004700$

0.38107300

0.04540000

$-1.07802000$

$-1.03543600$

$-2.07711500$

$-1.91346000$

$-2.96324300$

$-1.50646700$

$-1.90556100$

$-1.32436900$

$-2.27821200$

$-1.45582200$

0.31804800

1.40065100

$-0.12685700$

$-0.00070000$

1.22561700

1.88464600

1.83542100

0.43224800

$-0.46020300$

1.03492600

1.00683000

1.71299100

1.39977700

$-1.19099200$

2.79918600

2. 44516000

$-2.10281100$

0.02700900

$-0.22066200$

0.21168000 


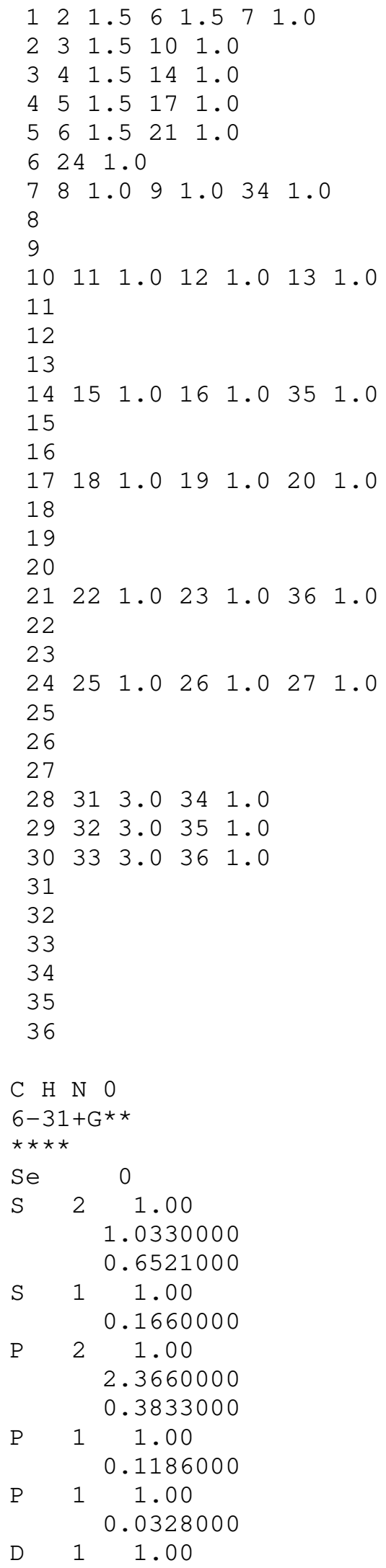



0.3630000
1.0000000

$\begin{array}{llll}S E & 0 & \\ S E-E C P & & 3 & 28\end{array}$

f-ul potential

5

$\begin{array}{rr}433.1931336 & -28.0000000 \\ 83.8952157 & -214.3841762 \\ 18.5839139 & -65.6918782 \\ 5.3955286 & -24.6153932 \\ 1.7474326 & -2.4481497\end{array}$

s-ul potential

$$
5
$$

202.8986193

78.3820487

35.0753037

10.8769543

2.8005941

p-ul potential

$$
5
$$

$0 \quad 44.3011875$

120.3874206

$2 \quad 23.1889948$

$2 \quad 7.9777664$

$2 \quad 2.2988146$

d-ul potential

5

73.3628263

48.3835618

25.6297211

7.1705822

1. 3639538

5.0000000

24.7973458

63.7575640

79.0512831

22.9520183

3.0000000

22.4705907

140.5492887

63.5781835

7.075361 